\title{
Cluster headaches associated with vascular malformations
}

\author{
L. HERZBERG, J. A. R. LENMAN, G. VICTORATOS, AND F. FLETCHER
}

From the Departments of Medicine and Radiology, University of Dundee, Dundee

SYNOPSIS A vascular malformation was demonstrated in a migrainous female who had developed@ cluster headaches. The patient responded well to oral dihydroergotamine $1 \mathrm{mg}$ twice daily.

The name 'periodic migrainous neuralgia' was first given in 1921 to a syndrome consisting of severe recurrent attacks of a knife-like unilateral pain in or around the eye (Harris, 1921). The pain is often intense and is sometimes designated as burning, pressing, or boring. It may spread to the forehead and the side of the head and neck, but not to the lips or tongue. The symptoms characteristically last from between 10 minutes to several hours and occur with remarkable regularity. The pain sometimes wakes a patient consistently at a particular time for periods of a week or more. The eye on the affected side becomes red and, at the height of the pain, the eye starts to water. Nasal stuffiness or sweating may occur. An increased appetite may follow the termination of the attack. Symptoms occur at least daily for up to several weeks at a time and this feature led to the introduction of the term 'cluster headaches' (Kunkle et al., 1952). There is complete freedom from attacks during the intervals. Although Symonds (1956) thoroughly reviewed the different descriptions of the condition and analysed 17 of his own cases, it is still not widely known.

Bickerstaff (1968) in an extensive review states 'no matter how consistently unilateral the symptoms may be, it is quite exceptional to demonstrate a vascular malformation' ... 'It is a well known and curious anomaly that, whereas in the past history of patients shown to have intracranial vascular malformation ... episodes indistinguishable from classic or common migraine, are often to be found ... the converse does not hold'. Symonds (1956) makes no mention of vascular malformations.

This communication therefore has a dual purpose. Firstly, it seeks to draw attention to the condition. Second, it records the finding of $a$ o vascular malformation in a female with a history $\overrightarrow{0}$ of attacks for 39 years.

\section{CASE REPORT}

The patient was a 55 year old district nurse whose $\overrightarrow{0}$ mother and maternal grandmother had headache She first developed headaches at the age of 16 years. They began with a flickering light over the left visualo field, persisting for about one hour. Fifteen to $30 \leq$ minutes after the onset of the visual disturbance, sheo would develop a right-sided throbbing headache $\frac{\mathrm{Q}}{\mathrm{O}}$

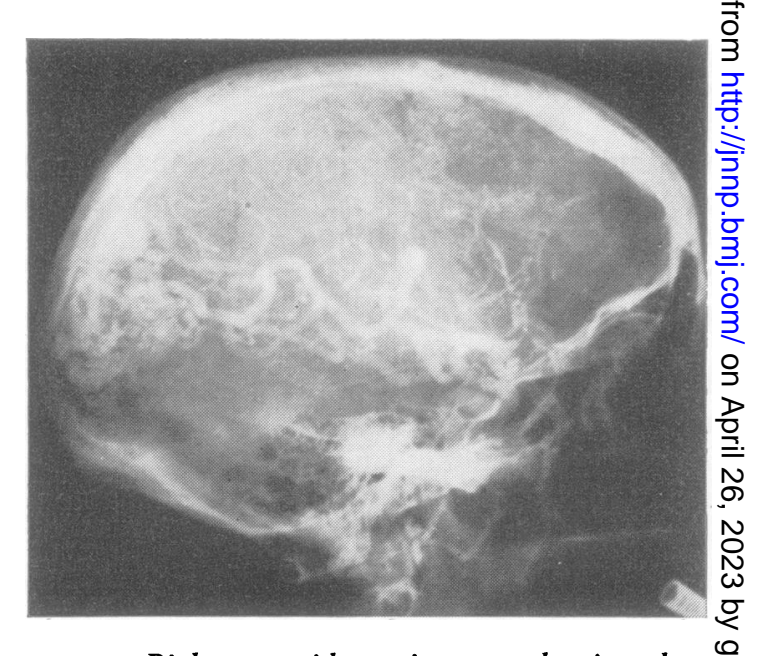

FIGURE Right carotid angiogram showing large $\frac{0}{\bar{\Phi}}$ arteriovenous malformation. 
lasting 24 or more hours. A Cafergot suppository (ergotamine tartrate $2 \mathrm{mg}$, caffeine $100 \mathrm{mg}$, belladonna alkaloids $0.25 \mathrm{mg}$, isobutylallyl barbituric acid $100 \mathrm{mg}$ ) would lead to the resolution of the headache within two hours. At the height of the headache, her right eye would start to water and the right nostril would feel congested. After 27 years of irregular headaches, a cyclical pattern began to emerge. They would occur frequently over a two month period with often a year or more of freedom between clusters.

The headaches became very severe in March 1974. In April, she had an episode in which she felt faint for a few minutes. There was no disturbance of consciousness. In June, she started vomiting in association with her usual throbbing right temporal headaches.

INVESTIGATIONS The only abnormal investigations were the EEG, brain scan, and carotid arteriogram. The former showed flicker responses to flash rates in excess of 20 per second. The brain scan showed an increased uptake of isotope in the right posterior parasagittal region. The right carotid angiogram showed a large arteriovenous anomaly supplied mainly by the posterior cerebral arteries (Figure).

\section{DISCUSSION}

FAMILY HISTORY The only cause of headaches frequently affecting close relatives is migraine. The frequency of a positive history varies according to different authors. Bickerstaff (1968) has found a positive history in about $70 \%$ of all cases, whereas Symonds (1956) found a $35 \%$ incidence. Our patient had a mother and grandmother with recurrent headaches; these could not be more fully described.

SEX INCIDENCE Males are affected four to six times as frequently as females. Fourteen of Symonds' 17 cases were males (1956). When females are affected, the time relationships described are often less precise and the bouts may last longer and be less clearly defined than in males (Bickerstaff, 1968).

TREATMENT Cluster headaches usually respond well to prophylactic injection of ergotamine tartrate. Both Symonds (1956) and Bickerstaff (1968) found that regular injections of $0.25 \mathrm{mg}$ of that drug three times daily stopped the attacks in those patients having several attacks a day. Symptoms ceased from the first day of treatment in over $80 \%$ of cases. A single nocturnal injection of $0.5 \mathrm{mg}$ often prevented patients being woken by the 'alarm clock headache'. Injections should be given for five days in every week, so that the effect of the treatment can be assessed during the two injection-free nights. If the cluster of headaches has not reached its end the attacks will persist and treatment will have to be resumed. Our patient responded well to dihydroergotamine $1 \mathrm{mg}$ orally twice daily and did not need injections.

\section{CONCLUSION}

Bickerstaff (1968) considered that the main failure to diagnose headaches of the type described here was the ignorance of its existence. He felt that it had been described too frequently under too many different names. For that reason, the original name and the name of 'cluster headaches' have been emphasized in this communication. It is suggested that, in common with the recommendation of the Ad Hoc Committee on Classification of Headache (1962), the term 'cluster headaches' should be used. It is an important condition which can be incapacitating and terrifying in its intensity. It is eminently treatable. The prognosis is favourable and there are rarely any significant sequelae. The demonstration of the vascular malformation in the case reported here is most unusual. The finding may be coincidental, especially in view of the strong family history of headache.

\section{REFERENCES}

Ad Hoc Committee on Classification of Headache (1962). A classification of headache. Neurology (Minneap.), 12, 378-380.

Bickerstaff, E. R. (1968). Cluster headaches. In Handbook of Clinical Neurology, vol. 5, pp. 111-118. Edited by P. J. Vinken and G. W. Bruyn. North-Holland: Amsterdam.

Harris, W. (1921). Persistent pain in lesions of the peripheral and central nervous system. Proceedings of the Royal Society of Medicine, 15, 13-24.

Kunkle, E. C., Pfeiffer, J. B., Jr, Wilhoit, W. M., and Hamrick, L. W., Jr (1952). Recurrent brief headache in 'cluster' pattern. Transactions of the American Neurclogical Association, 77, 240-243.

Symonds, C. P. (1956). A particular variety of headache. Brain, 79, 217-232. 